\title{
Preoperative chemoradiation versus radiation alone for stage II and III resectable rectal cancer (Review)
}

Ceelen WP, Van Nieuwenhove Y, Fierens K

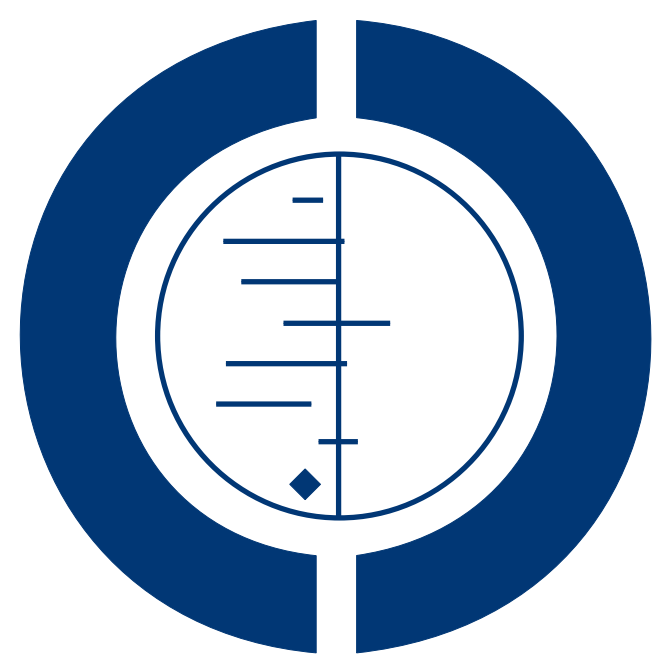

\section{THE COCHRANE COLLABORATION $^{\circledR}$}

This is a reprint of a Cochrane review, prepared and maintained by The Cochrane Collaboration and published in The Cochrane Library 2009, Issue 1

http://www.thecochranelibrary.com

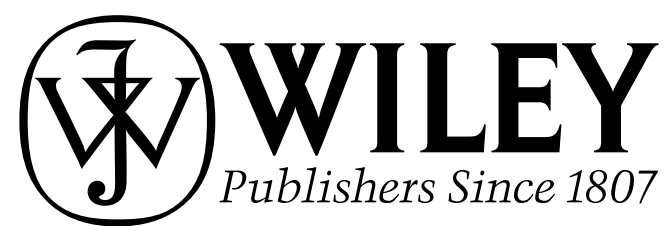

Preoperative chemoradiation versus radiation alone for stage II and III resectable rectal cancer (Review)

Copyright (C) 2009 The Cochrane Collaboration. Published by John Wiley \& Sons, Ltd. 
TABLE OF CONTENTS

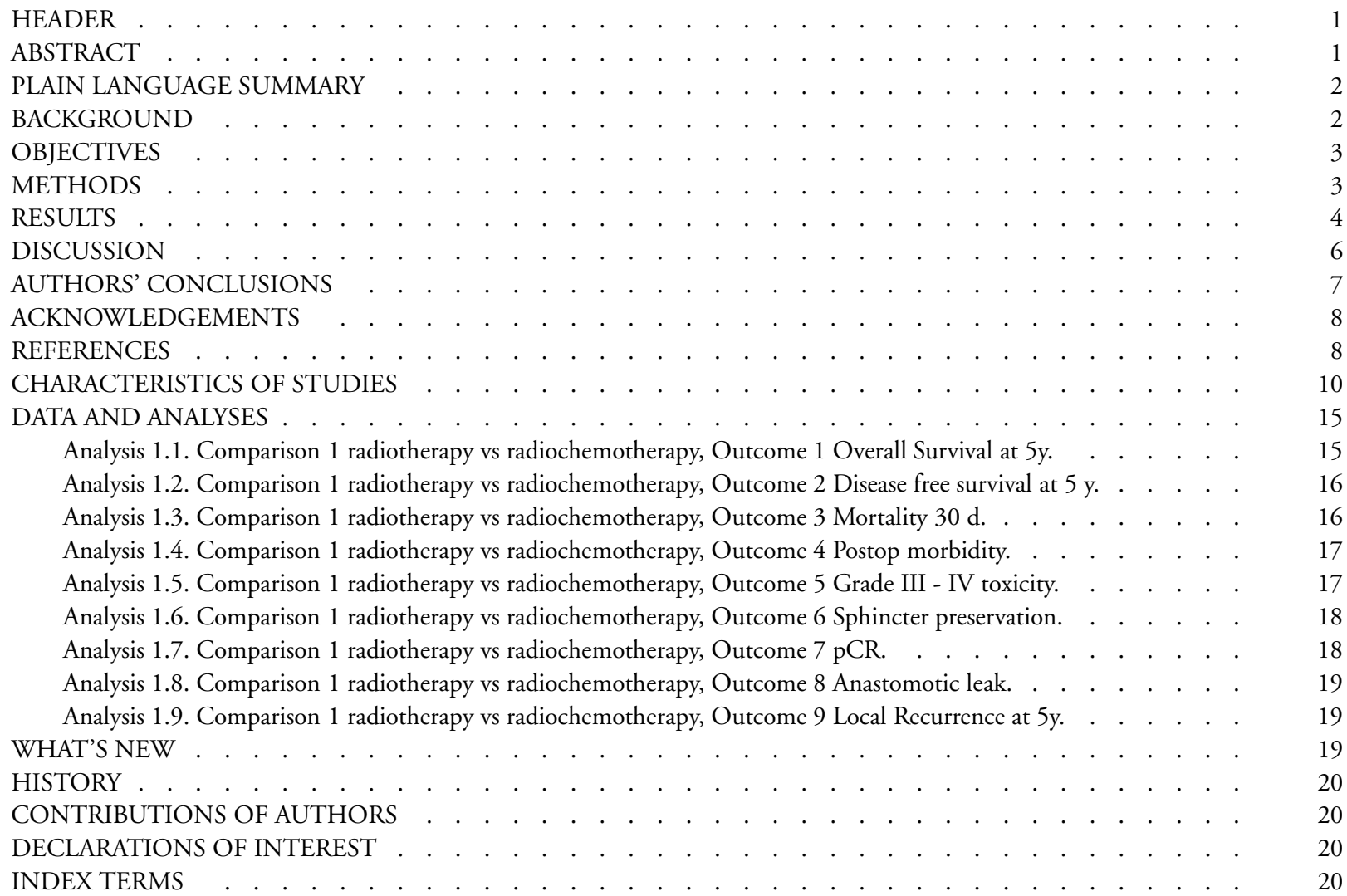

Preoperative chemoradiation versus radiation alone for stage II and III resectable rectal cancer (Review)

Copyright @ 2009 The Cochrane Collaboration. Published by John Wiley \& Sons, Ltd. 


\title{
[Intervention Review]
}

\section{Preoperative chemoradiation versus radiation alone for stage II and III resectable rectal cancer}

\author{
Wim P Ceelen ${ }^{1}$, Yves Van Nieuwenhove ${ }^{2}$, Kjell Fierens ${ }^{3}$ \\ ${ }^{1}$ Dept. of Surgery 2K12 1C, Ghent University Hospital, Ghent, Belgium. ${ }^{2}$ Department of Experimental Surgery, Free University of \\ Brussels, Brussels, Belgium. ${ }^{3}$ Dept. of Surgery 2 K12 1c, Ghent University Hospital, Ghent, Belgium \\ Contact address: Wim P Ceelen, Dept. of Surgery 2K12 1C, Ghent University Hospital, De Pintelaan 185, Ghent, B-9000, Belgium. \\ wim.ceelen@ugent.be.
}

Editorial group: Cochrane Colorectal Cancer Group.

Publication status and date: New, published in Issue 1, 2009.

Review content assessed as up-to-date: 1 September 2008.

Citation: Ceelen WP, Van Nieuwenhove Y, Fierens K. Preoperative chemoradiation versus radiation alone for stage II and III resectable rectal cancer. Cochrane Database of Systematic Reviews 2009, Issue 1. Art. No.: CD006041. DOI: 10.1002/14651858.CD006041.pub2.

Copyright (C) 2009 The Cochrane Collaboration. Published by John Wiley \& Sons, Ltd.

\begin{abstract}
A B S T R A C T
Background

Preoperative radiotherapy (RT) decreases local recurrence rate and improves survival in stage II and III rectal cancer patients. The combination of chemotherapy with RT has a sound radiobiological rationale, and phase II trials of combined chemoradiation (CRT) have shown promising activity in rectal cancer.
\end{abstract}

Objectives

To compare preoperative RT with preoperative CRT in patients with resectable stage II and III rectal cancer.

Search strategy

We searched the Cochrane Central Register of Controlled Trials, Web of Science, Embase.com, and Pubmed from 1975 until june 2007. A manual search was performed of Ann Surg, Arch Surg, Cancer, J Clin Oncol, Int J Radiat Oncol Biol Phys and the proceedings of ASTRO, ECCO and ASCO from 1990 until june 2007.

Selection criteria

Relevant studies randomized resectable stage II or III rectal cancer patients to at least one arm of preoperative RT alone or at least one arm of preoperative CRT.

Data collection and analysis

Primary outcome parameters included overall survival (OS) at 5 years and local recurrence (LR) rate at 5 years. Secondary outcome parameters included disease free survival (DFS) at 5 years, metastasis rate, pathological complete response rate, clinical response rate, sphincter preservation rate, acute toxicity, postoperative mortality and morbidity, and anastomotic leak rate. Outcome parameters were summarized using the Odds Ratio (OR) and associated 95\% confidence interval (CI) using the fixed effects model.

Main results

Four trials were identified and included in the meta-analysis. The addition of chemotherapy to preoperative RT significantly increased grade III and IV acute toxicity (OR 1.68-10, $\mathrm{P}=0.002$ ) while no differences were observed in postoperative morbidity or mortality. Compared to preoperative RT alone, preoperative CRT significantly increased the rate of complete pathological response (OR 2.52-

Preoperative chemoradiation versus radiation alone for stage II and III resectable rectal cancer (Review)

Copyright @ 2009 The Cochrane Collaboration. Published by John Wiley \& Sons, Ltd. 
5.27, $\mathrm{P}<0.001)$ although this did not translate into a higher sphincter preservation rate (OR 0.92-1.31, $\mathrm{P}=0.29)$. The indidence of local recurrence at five years was significantly lower in the CRT group compared to RT alone (OR 0.39-0.72, $\mathrm{P}<0.001)$. No statistically significant differences were observed in DFS (OR 0.92-1.34, $\mathrm{P}=0.27$ ) or OS (OR 0.79-1.14, $\mathrm{P}=0.58)$ at five years.

\section{Authors' conclusions}

Compared to preoperative RT alone, preoperative CRT enhances pathological response and improves local control in resectable stage II and III rectal cancer, but does not benefit disease free or overall survival. The effects of preoperative CRT on functional outcome and quality of life are incompletely understood and should be addressed in future trials.

\section{PLAIN LANGUAGE SUMMARY}

\section{Preoperative chemoradiation versus radiation alone for stage II and III resectable rectal cancer}

In rectal cancer patients, local control is improved by administering radiotherapy (RT) before surgery. Recently, studies have combined preoperative RT with chemotherapy aiming to further improve local control. This review compared preoperative RT with preoperative chemoradiation (CRT) in patients with stage II and III rectal cancer.

Based on the combined analysis of four randomized studies, we found that compared to preoperative RT alone, preoperative CRT enhances pathological response and improves local control in resectable stage II and III rectal cancer, but does not benefit disease free or overall survival. Combined CRT enhances treatment related acute toxicity, but does not affect postoperative complication rate. The effects of preoperative CRT on functional outcome and quality of life are incompletely understood and should be addressed in future trials.

\section{B A C K G R O U N D}

The incidence of fatal cases of colorectal cancer in Europe exceeds 200.000 per year. Due to the specifc anatomy and biology of rectal cancer, surgery alone historically has been associated with local recurrence in up to one in four patients. Locally recurrent disease is usually incurable, causes important morbidity and suffering and gives rise to systemic metastases. In the last few decades, improvements in surgical technique have dramatically lowered the incidence of locally recurrent disease. Careful pathological studies have clearly demonstrated that the major cause of local recurrence is the persistence of tumor foci within the mesorectum (Quirke 1986; Quirke 2003). Intact removal of the entire mesorectum (total mesorectal excision or TME) in cancers of the mid or lower third of the rectum was pioneered by Heald and has resulted in local recurrence rates lower than 5-10\% (Heald 1982; Heald 1998; Enker 1999). The importance of complete removal of the surrounding mesorectum necessitates precise preoperative evaluation of the circumferential resection margin using imaging. Recently, magnetic resonance imaging (MRI) using a phased array coil has emerged as the imagign modality of choice in the preoperative evaluation of locally advanced rectal cancer Beets-Tan 2003; Beets-
Tan 2005; Brown 2004; Daniels 2005; Brown 2006).

Parallel to improvements in surgical technique, adjuvant therapy regimens have been tested in clinical trials in an effort to reduce local recurrence rates. Neoadjuvant radiotherapy (RT) has been shown to significantly decrease local recurrence rate and improve survival provided a biologically equivalent dose (BED) of at least $30 \mathrm{~Gy}$ is administered (Gray 2001). The advantages of preoperative over postoperative RT include enhanced effectiveness in well oxygenated tissue, downstaging of advanced tumors and better treatment compliance (Glimelius 2002). This theoretical superiority of the preoperative approach over postoperative adjuvant therapy has been confirmed in the recent German rectal cancer trial (Sauer 2004). The effect of preoperative RT on local recurrence rate is consistent even when optimal surgical technique (TME) is implemented. This was demonstrated by the results of the Dutch rectal cancer trial which randomized rectal cancer patients to undergo either RT followed by TME or TME alone in the setting of a national surgical training programme (Kapiteijn 2001). Compared to TME alone, 5x5 Gray (Gy) of RT followed by TME resulted in a significantly lower local recurrence rate, although no 
improvement in overall survival (OS) was noted.

Although preoperative RT results in a significant pathological response in a minority of patients, significant downsizing is rarely achieved using short schedule RT regimens. In order to improve tumor response, preoperative RT has been combined with chemotherapeutic regimens. There is a strong radiobiological rationale to combine RT with chemotherapy. Combined chemoradiation (CRT) for rectal cancer was introduced in the adjuvant setting and subsequently in irresectable disease, where significant downsizing and downstaging was observed in many patients (Minsky 1993; Minsky 1997). The argument for preoperative CRT in resectable disease is based primarely on possible downsizing and downstaging of tumors close to the circumferential resection margin or the sphincter apparatus, thereby enhancing both $\mathrm{R} 0$ resection and the sphincter preservation rate. The paramount importance of performing the resection with a negative CRM was shown in several clinical studies (Nagtegaal 2002). Secondly, the addition of chemotherapy could eliminate microscopic systemic disease present at the time of surgery. Possible concerns of preoperative CRT include an increase of both local and systemic toxicity and overtreatment of inaccurately staged patients (Ammann 2003). Several phase I and II studies using preoperative CRT have shown a promising tumor response with acceptable toxicity (Rodel 2003; Osti 2004). A limited number of prospective randomized trials comparing preoperative RT alone with preoperative CRT in resectable rectal cancer are published or ongoing.

\section{O B J E C T IV E S}

To compare preoperative RT with preoperative CRT in patients with resectable stage II or III rectal cancer.

\section{METHODS}

\section{Criteria for considering studies for this review}

\section{Types of studies}

Randomized controlled trials (RCT's) which randomize patients before surgery with curative intent to one of at least two schedules of preoperative therapy including RT and CRT.

\section{Types of participants}

Patients with clinical stage II or III resectable rectal cancer undergoing preoperative RT or CRT followed by surgery.

\section{Types of interventions}

Preoperative RT or CRT using fractionated external radiotherapy followed by surgery with curative intent (resectable rectal cancer). The surgical procedure must consist of rectal amputation or sphincter preserving anterior resection using an open or laparoscopic approach; local excisions are excluded.

\section{Types of outcome measures}

Primary

-local recurrence rate at 5 years

Secondary

-overall survival at 5 years

-disease free survival at 5 years

-systemic metastasis rate

-pathological complete response rate

-clinical response rate

-sphincter preservation rate

- postoperative mortality within 30 days

- postoperative morbidity

- anastomotic leak rate

\section{Search methods for identification of studies}

See: Colorectal Cancer Group methods used in reviews. We searched the following electronic databases -Cochrane Central Register of Controlled Trials

-ISI Web of Science (Science Citation Index, Current Contents) from 1975 until june 2007

-Embase.com

-Pubmed

Electronic database searches were performed with $\mathrm{MeSH}$ terms and free text terms:

-MeSH: \Rectal Neoplasms"[MeSH] AND

Radiotherapy”[MeSH] AND IDrug Therapy “[MeSH]

-Free text terms:

rectal, rectum, cancer, adenocarcinoma, neoplasm, radiotherapy, irradiation, chemotherapy, chemoradiation, radiochemotherapy, combined modality, multimodal,preoperative,neoadjuvant Manual search/abstract search

- Journals from 1990: Ann Surg, Arch Surg, Cancer, J Clin Oncol, Int J Radiat Oncol Biol Phys

- Proceedings from ASTRO, ECCO and ASCO

No language constraints were applied.

\section{Data collection and analysis}

All three reviewers (WPC, KF, YVN) obtained the full text of all relevant studies and were assessed for methodological quality according to the Cochrane Collaboration's tool for assessing the risk of bias (Higgins 2008). Methodological details relevant for 
potential bias included sequence generation, allocation concealment, bliniding, incomplete outcome data, and selective outcome reporting. Disagreement was resolved by consensus.

Data were extracted by one reviewer (KF) on custom designed forms and entered in a computer database for transfer and statistical analysis in the Review Manager software. The data extracted included first author, year of publication, source, method of preoperative therapy and surgery, method of randomization, number of patients included, randomized, and analyzed, and outcome parameters as listed above. Data accuracy was verified by the senior author (WPC).

RT dose was converted to the biologically equivalent dose (BED) using the linear quadratic equivalent formula (Dale 2005): BED $=\mathrm{nd}\left(1+1 /(\alpha / \beta)-(\gamma / \alpha)\left(\mathrm{T}-\mathrm{T}_{k}\right)\right.$, with $\mathrm{n}=$ number of fractions, $\mathrm{d}$ $=$ dose per fraction, $\alpha / \beta=$ the linear quadratic quotient (set at $10 \mathrm{~Gy}$ ), $\gamma / \alpha=$ repair rate (set at $0.6 \mathrm{~Gy} / \mathrm{d}$ ), and $\mathrm{T}_{k}=$ the initial time delay in days (set at 7). Differences between categorical outcome parameters were quantified using the odds ratio $(\mathrm{OR})$ and corresponding $95 \%$ confidence interval (95CI). Summary statistics were calculated using the Mantel-Haenszel methods. Heterogeneity analysis was performed using the $\mathrm{Q}$ test, with significance accepted when $\mathrm{P}<0.1$. When present, heterogeneity will be addressed as recommended by the Cochrane Collaboration Handbook (Higgins 2008).

\section{RE S U L T S}

\section{Description of studies}

See: Characteristics of included studies.

Of a total of 17925 studies resulting from the primary search, 324 papers were selected for full review. In all, 320 papers were discarded (Table 1). Four randomized trials were identified comparing preoperative RT with preoperative CRT is resectable stage II or III rectal cancer (Bosset 2006; Boulis-Wassif 1984; Bujko 2006; Gerard 2006).

Table 1. excluded studies

\begin{tabular}{l|l}
\hline Type & N \\
\hline Non randomized trials & 144 \\
\hline Adjuvant therapy trials & 28 \\
\hline $\begin{array}{l}\text { Trials not including at least one chemotherapy arm combined with } \\
\text { radiotherapy }\end{array}$ & 71 \\
\hline
\end{tabular}


Table 1. excluded studies (Continued)

\begin{tabular}{l|l}
\hline Trials not including radiotherapy & 27 \\
\hline Trials using local or no resection & 18 \\
\hline Trials including other tumor types & 25 \\
\hline Trials not including stage II/III cancer & 7 \\
\hline Total & 320 \\
\hline
\end{tabular}

From November 1972 through April 1976, Boulis-Wassif et al. recruited 247 patients with histologically proven localized adenocarcinoma of the rectum and no clinical of surgical evidence of distant metastases. All patients in both groups received preoperative RT by two parallel opposing diamond and chimney fields. All patients received a total dose of 34.5 Gy in 15 fractions of 2.3 Gy each over a total treatment time of 18 days $(\mathrm{BED}=35.8 \mathrm{~Gy})$. In the preoperative CRT group, intravenous 5-FU injection $(375$ $\mathrm{mg} / \mathrm{m} 2$ ) was administered during the first 4 days of irradiation. Surgery usually followed within 2 weeks after the last irradiation. Two patients died before surgery. Assessed outcomes included ease of surgery, type of operation, radical resectability rate, histopathological response, postoperative mortality, postoperative period of hospitalization, local control of the disease, distant metastases, disease free survival, and median survival. Follow-up was available up to 7 years.

From April 1999 until February 2002, Bujko et al. included 316 patients with resectable T3-T4 rectal carcinoma without sphincter infiltration and with a lesion accessible to digital rectal examination. Patients were randomised to either preoperative 5 x 5 Gy short-term RT (BED = 37.5 Gy) with subsequent total mesorectal excision (TME) performed within 7 days or to CRT to a total dose of 50.4 Gy (1.8 Gy per fraction during 25 days; BED $=42.2$ Gy) concomitantly with two courses of bolus 5-fluorouracil (325 $\mathrm{mg} / \mathrm{m} 2$ ) and leucovorin during weeks 1 and 5 of RT. Chemoradiation was followed by TME after 4-6 weeks. Three patients did not undergo surgery. Assessed outcomes were acute postirradiation toxicity, sphincter preservation rate, postoperative mortality, pathology, overall survival, disease free survival, local recurrence rate, distant metastases, late toxicity and incidence of permanent stoma. Median follow up was 48 months.

Between April 1993 and November 2003, Gerard et al. recruited 762 patients with a histologically confirmed, previously untreated rectal adenocarcinoma accessible to digital rectal examination (T3 or resectable T4 tumor with no evidence of distant metastases). Patients were allocated to two treatment arms: preoperative RT vs. preoperative CRT, both followed by surgery. RT was delivered with photons from a linear accelerator in a three- or four-field box technique. The dose per fraction was 1.8 Gy and all fields were treated each day with five fractions per week. The total dose was $45 \mathrm{~Gy}$ in 25 fractions during 5 weeks $(\mathrm{BED}=42.2 \mathrm{~Gy})$. Concurrent chemotherapy (CT) consisted of bolus 5-fluorouracil (350 $\mathrm{mg} / \mathrm{m} 2$ ) and leucovorin administered during week 1 and 5 of RT. Surgery was planned between 3 and 10 weeks after the end of the preoperative RT (+/-CT). TME was recommended. Assessed outcomes were surgical procedures and postoperative complications, pathology, overall survival, progression frees survival and local recurrence. Median follow-up was 81 months.

Between April 1993 and March 2003, Bosset et al. recruited 1011 patients with a T3 or resectable T4 M0 adenocarcinoma of the rectum within $15 \mathrm{~cm}$ from the anal margin and without previous treatment for this disease (EORTC 22921 trial). Patients were allocated to four treatment arms: preoperative RT, preoperative CRT, preoperative RT plus postoperative CT and preoperative CRT plus postoperative CT. RT consisted of 45 Gy delivered to the posterior pelvis in 25 fractions of $1.8 \mathrm{~Gy}$ over a period of 5 weeks $(\mathrm{BED}=42.2 \mathrm{~Gy})$. The target volume of RT was not a classical pelvic volume but was limited to the main field of tumor spread and to the perirectal nodes. Preoperative chemotherapy was delivered in two 5 -day courses of 5 -fluorouracil $(350 \mathrm{mg} / \mathrm{m} 2)$ with leucovorin during the first and fifth weeks of RT. Surgery was scheduled to take place 3 to 10 weeks after treatment. TME was recommended beginning in 1999. Assessed outcomes were toxicity of the preoperative treatment, performed surgical procedures, rate of postoperative complications, pathology, late side effects, overall survival, disease free survival, local and distant recurrence rate. Median follow-up of 5.4 years. 


\section{Risk of bias in included studies}

Randomisation was adequately performed in all four studies using communication with a central office. Three studies based randomisation on the minimization method (Bujko 2006; Gerard 2006; Bosset 2006). In the fourth study, the randomisation method is not specified (Boulis-Wassif 1984). None of the studies were described as doube blind or used blinded outcome assessment.. Description of withdrawals and dropouts was given in all four studies. There were no imbalances between treatment arms in the number of patients that did not undergo the complete trial procedure. Three studies were performed on an intention-to-treat basis (Bujko 2006; Gerard 2006; Bosset 2006); no imbalances were identified between treatment arms.

\section{Effects of interventions}

The main primary outcome parameter was the local recurrence rate at five years, which was reported in three studies (Bosset 2006; Boulis-Wassif 1984; Gerard 2006). In the RT group, 122 of 740 patients $(16.5 \%)$ developed a local recurrence while in the CRT group this event was observed in 71 out of 754 patients (9.4\%). This difference was statistically significant (OR 0.53 , 95\%CI 0.39 $0.72, \mathrm{P}<0.001)$. No statistically significant heterogeneity among studies was present $(P=0.12)$. Survival data at 5 years were available in three studies (Bosset 2006; Boulis-Wassif 1984; Gerard 2006). In the CRT group, 644 of 1007 patients (63.9\%) were alive at 5 years while in the RT group 647 of 993 patients (65.2\%) survived 5 years. This difference did not reach statistical significance (OR 0.95, 95\%CI 0.79-1.14, $\mathrm{P}=0.58)$. No heterogeneity was present $(\mathrm{P}=0.15)$.

The results of the analysis of the secondary outcome parameters were as follows. Disease free survival at 5 years, available in the studies of Bosset 2006 and Gerard 2006, was 507/881 (57.5\%) in the CRT group and $479 / 872(54.9 \%)$ in the RT group. This difference was not statistically significant (OR 1.11, 95\%CI 0.92$1.34, \mathrm{P}=0.27)$. Significant heterogeneity did not occur $(\mathrm{P}=$ 0.64). Grade III or IV treatment related toxicity developed in 151 of 1015 patients (14.9\%) treated with CRT while in patients treated with RT alone, this occurred in 52 of 1017 patients (5.1\%). This difference was statistically significant (OR 4.1, 95\%CI 1.68$10, \mathrm{P}=0.002)$. There was, however, significant heterogeneity ( $\mathrm{P}$ $=0.005)$ which remained when the data were reanalysed using the random effects assumption. Among patients who underwent surgery, sphincter preservation was possible in 551 of $1111 \mathrm{pa}-$ tients (49.6\%) in the CRT group and in 527 of 1108 patients (47.6\%) in the RT group; this difference failed to reach statistical significance (OR 1.1, 95\%CI 0.92-1.31, P = 0.29). No heterogeneity was observed $(\mathrm{P}=0.48)$. Postoperative 30 day mortality was observed in 31 of $1122(2.8 \%)$ patients in th CRT group and in 21 of $1117(1.9 \%)$ patients in the RT group. This difference did not reach statistical significance (OR 1.48, 95\%CI 0.84-2.6, $\mathrm{P}=0.17)$; no heterogeneity was detected $(\mathrm{P}=0.6)$. Similarly, no significant differences were observed in postoperative morbidity or anastomotic leak rate (OR 0.68-1.03, P = 0.1 and OR 0.57$1.85, \mathrm{P}=0.93$ respectively). Pathological complete response (ie, ypT0N0) of the resected specimen was observed in 129 of 1096 patients $(11.8 \%)$ in the CRT group and in 39 of 1105 patients $(3.5 \%)$ in the RT group. This difference was statistically significant (OR 3.65, 95\%CI 2.52-5.27, $\mathrm{P}<0.001$ ) while significant heterogeneity for this parameter was not observed $(\mathrm{P}=0.15)$. Because of the limited number of included studies, no sensitivity analysis was performed.

\section{I S C U S S I O N}

Preoperative RT has been shown to reduce local recurrence rates and marginally improve survival over surgery alone provided a $\mathrm{BED}>30 \mathrm{~Gy}$ is delivered to the target region (Gray 2001). The current review addresses the question whether the addition of chemotherapy to preoperative RT further enhances pathological and clinical outcome parameters. Four randomized trials were identified comparing preoperative CRT with preoperative RT alone in resectable, locally advanced rectal cancer. Although there was considerable variation in radiotherapy dose and fractionation, all four studies have used a BED > $30 \mathrm{~Gy}$. In three trials (Gerard 2006; Boulis-Wassif 1984; Bosset 2006), RT regimens were identical in both groups. In the Polish study (Bujko 2006), RT dose and fractionation and time interval until surgery were different in both groups $(5 \times 5$ Gy followed by immediate surgery versus 50.4 Gy followed by surgery after a waiting period of 4-6 weeks). In this study, therefore, it remains unclear whether the observed differences in tumor response between both arms are attributable to the addition of chemotherapy or to a different RT schedule and a different waiting period until surgery. Since, moreover, actuarial local recurrence data at five years are not available in this study, it was left out from the meta-analysis of local recurrence at five years. This analysis demonstrates a significant reduction in local recurrence rate with the addition of chemotherapy (OR 0.39-0.72, $\mathrm{P}<$ 0.001). Importantly, the cumulative incidence rates of local recurrence in the RT group of the studies of Bosset 2006 and Gerard 2006 (17\%) and in both groups of the study of Boulis- Wassif 1984 (15\%) seem high compared to the $5.5 \%$ local recurrence rate at five years achieved by the Dutch rectal cancer trial using $5 \times 5$ Gy preoperative RT followed by surgery (van den Brink 2004). Differences in stage distribution and variation in surgical technique might explain this observation. Indeed, during the Dutch rectal cancer trial a formal surgical training and quality control program was implemented in order to guarantee optimal surgery (TME). The study of Boulis-Wassif 1984 predated the introduction of TME surgery (inclusion period 1972-1976), whereas in the studies of Bosset 2006 and Gerard 2006, TME surgery was 'recommended' without any formal surgical training or quality control. 
Although in the study of Boulis-Wassif 1984 a marginally significant five year survival benefit was associated with CRT, the combined analysis failed to demonstrate a significant difference in either overall or disease free survival at five years (OR 0.79-1.14, $\mathrm{P}$ $=0.58$ and OR $0.92-1.34, P=0.27$, respectively). One of the hypotheses formulated to explain the observed lack of survival benefit found in many pre- or postoperative adjuvant therapy trials in rectal cancer is the existence of early, subclinical systemic disease present at diagnosis. This hypothesis is supported by the finding that the rate of distant metastatic disease in all four trials is consistently around 30\%, without any difference between CRT and RT groups, indicating a future role of more effective systemic therapy to eradicate micrometastatic disease from the onset of therapy. Others have argued that the follow up time of the included trials is too short to observe a survival benefit, or that the incidence of local recurrence is too low to influence survival (Gerard 2006).

Grade III and IV acute treatment related toxicity was more pronounced in the CRT group in the three studies reporting this parameter (Bosset 2006; Bujko 2006; Gerard 2006), with an overall OR of 1.68-10 and a P value of 0.002. However, chemotherapy related toxicity was generally acceptable as evidenced by the high compliance rates in the studies mentioned $(82 \%, 78.1 \%$, and $69 \%$ respectively). In resected patients, no differences were observed in 30 day mortality, postoperative morbidity, or anastomotic leak rate. The results concerning anastomotic leakage should be interpreted with caution, since the exceedingly low leakage rate in the study of Bosset compared to currently accepted and published leakage rates following anterior resection suggests underreporting of this specific complication.

Postoperative quality of life (QoL) is an important, though often underreported aspect of cancer trials. From the Swedish and Dutch rectal cancer trials, it is known that preoperative $5 \times 5$ Gy followed by surgery significantly worsens functional outcome in terms of bowel, sexual, and bladder function compared to surgery alone (Holm 1996; Dahlberg 1998; Peeters 2005). A number of phase II trials have suggested that preoperative CRT followed by surgery does not adversely affect functional outcome (Feliu 2002; Bosset 2000). The scarce available data in the four included studies did not allow to perform a meta-analysis fo QoL related parameters. However, preliminary functional outcome data of the EORTC 22921 study (published as abstract only) demonstrated a significantly worse anorectal function in CRT patients compared to RT alone (Mercier 2005). Interestingly, in the final results paper of this study the incidence of 'late side effects' including fecal incontinence did not seem to differ between the four treatment arms (Bosset 2006).

The results of the meta-analysis confirm the enhanced cytotoxic efficacy of combined RT with 5-fluorouracil based chemotherapy. The incidence of a complete pathological response ( $\mathrm{pCR}$, ypT0N0) was 129 of $1096(11.8 \%)$ patients in the CRT group and 39 of 1105 (3.5\%) patients in the RT group; this difference was statistically highly significant (OR 3.65, 95\%CI 2.52-5.27, P $<0.001$ ) while no heterogeneity was observed between the four studies. The results of the EORTC study moreover confirmed the difference in radioresponsiveness of the tumor in the bowel wall compared to that of mesorectal lymph nodes, as evidenced by nodal involvement in up to $12 \%$ of ypT0 patients (Bosset 2004). Although in two studies (Bosset 2006; Boulis-Wassif 1984) a trend towards increased sphincter preservation was observed in the CRT group, the overall results failed to demonstrate an increase in sphincter preserving surgery following CRT (OR 0.92$1.31, \mathrm{P}=0.29$ ), notwithstanding the downsizing and downstaging effect often noted with the combined therapy. This finding may be related to reluctance of the colorectal surgeon to alter a preoperative assessment of the need to perform a rectal amputation, since reversal of this decision would possibly imply performing an anastomosis in previously macroscopically invaded tissue. Moreover, in at least two studies was it specifically advised not to change a preoperative decision to perform a rectal amputation even after a significant downsizing. Data from the German rectal cancer trial, however, suggested that a change in operative strategy (ie, perform sphincter preserving surgery when a significant clinical response is observed) may be safely performed. Longer follow up will be needed to confirm the safety of this approach.

\section{AUTHORS' CONCLUSIONS}

\section{Implications for practice}

Compared to preoperative RT alone, preoperative CRT enhances tumor reponse and improves local recurrence rates. Therefore, the addition of CT should be considered when the tumor is located close $(<2 \mathrm{~mm})$ to the circumferential resection marging or the sphincter apparatus. The addition of chemotherapy causes a moderate increase in acute toxicity, although postoperative complications including anastomotic leakage are not enhanced.

At this moment, it is unclear from the available data whether the addition of chemotherapy to preoperative RT influences sphincter preservation. Patients should be informed about the possible functional and QoL related aspects of preoperative therapy.

\section{Implications for research}

1. Since the improvement of local control obtained with CRT did not translate into a better overall or disease free survival and up to one third of all patients develop distant spread, priority should be given to trials addressing early subclinical systemic spread;

2. Trials are needed that specifically address the oncological safety of performing sphincter preserving surgery (including intersphincteric resection and colo-anal anastomosis) in patients deemed to require amputation before the start of CRT and in whom a significant clinical response is observed; 
3. Preoperative therapy trials in rectal cancer should include formal evaluation of functional and QoL related aspects of therapy.

\section{ACKNOWLEDGEMENTS}

None

\section{R E F E R E N C E S}

\section{References to studies included in this review}

\section{Bosset 2006 \{published data only\}}

Bosset JF, Collette L, Calais G, Mineur L, Maingon P, RadosevicJelic L, Daban A, Bardet E, Beny A, Ollier JC, EORTC Radiotherapy Group Trial 22921. Chemotherapy with Preoperative Radiotherapy in Rectal Cancer. The New England Journal of Medicine 2006;355:1114-23.

\section{Boulis-Wassif 1984 \{published data only\}}

S. Boulis-Wassif, A. Gerard, J. Loygue, D. Camelot, M. Buyse, N. Duez. Final Results of a Randomized Trial on the Treatment of Rectal Cancer with Preoperative Radiotherapy Alone or in Combination With 5-Fluorouracil, Followed by radical surgery. Cancer 1984;53:1811-1818.

Bujko 2006 \{published data only\}

Bujko K, Nowacki MP, Nasierowska-Guttmejer A, Michalski W, Bebenek M, Kryj M. Long-term results of a randomized trial comparing preoperative short-course radiotherapy with preoperative conventionally fractionated chemoradiation for rectal cancer. British Journal of Surgery 2006;93:1215-1223.

Gerard 2006 \{published data only\}

Jean-Pierre Gérard, Thierry Conroy, Franck Bonnetain, Olivier Bouché, Olivier Chapet, Marie-Thérèse Closon-Dejardin, Michel Untereiner, Bernard Leduc, Eric Francois, Jean Maurel, JeanFrancois Seitz, Bruno Buecher, Rémy Mackiewicz, Michel Ducreux, Laurent Bedenne. Preoperative Radiotherapy With or Without Concurrent Fluorouracil and Leucovorin in T3-T4 Rectal Cancers: Results of FFCD 9203. J Clin Oncol 2006;24:4620-4625.

\section{Additional references}

\section{Ammann 2003}

Ammann K, Kirchmayr W, Klaus A, Muhlmann G, Kafka R, Oberwalder M, De Vries A, Ofner D, Weiss H. Impact of neoadjuvant chemoradiation on anal sphincter function in patients with carcinoma of the midrectum and low rectum. Archives of Surgery 2003;138(3):257-261.

Beets-Tan 2003

Beets-Tan RGH, Beets GL. Rectal cancer: how accurate can imaging predict the $\mathrm{T}$ stage and the circumferential resection margin?. International Journal of Colorectal Disease 2003;18(5): 385-391.
Beets-Tan 2005

Beets-Tan RGH, Lettinga T, Beets GL. Pre-operative imaging of rectal cancer and its impact on surgical performance and treatment outcome. Ejso 2005;31(6):681-688.

\section{Bosset 2000}

Bosset JF, Magnin V, Maingon P, Mantion G, Pelissier EP, Mercier M, Chaillard G, Horiot JC. Preoperative radiochemotherapy in rectal cancer: Long-term results of a phase II trial. International Journal of Radiation Oncology Biology Physics 2000;46(2):323-327.

\section{Bosset 2004}

Bosset JF, Calais G, Daban A, Berger C, Radosevic-Jelic L, Maingon P, Bardet E, Pierart M, Briffaux A. Preoperative chemoradiotherapy versus preoperative radiotherapy in rectal cancer patients: assessment of acute toxicity and treatment compliance - Report of the 22921 randomised trial conducted by the EORTC Radiotherapy Group. European Journal of Cancer 2004;40(2):219-224.

Brown 2004

Brown G, Kirkham A, Williams GT, Bourne M, Radcliffe AG, Sayman J, Newell R, Sinnatamby C, Heald RJ. High-resolution MRI of the anatomy important in total mesorectal excision of the rectum. American Journal of Roentgenology 2004;182(2):431-439. [: 0361-803X]

\section{Brown 2006}

Brown G, Daniels IR, Heald RJ, Quirke P, Blomqvist L, SebagMontefiore D, Moran BJ, Holm T, Strassbourg J, Peppercorn PD, Fisher SE, Mason B. Diagnostic accuracy of preoperative magnetic resonance imaging in predicting curative resection of rectal cancer: prospective observational study. British Medical Journal 2006;333 (7572):779-782. [: 0959-8146]

Dahlberg 1998

Dahlberg M, Glimelius B, Graf W, Pahlman L. Preoperative irradiation affects functional results after surgery for rectal cancer Results from a randomized study. Diseases of the Colon \& Rectum 1998;41(5):543-549.

Dale 2005

Dale R, Carabe-Fernandez A. The radiobiology of conventional radiotherapy and its application to radionuclide therapy. CANCER BIOTHERAPY AND RADIOPHARMACEUTICALS 2005;20 (1):47-51. 


\section{Daniels 2005}

Daniels IR. High spatial resolution MRI predicts turnout spread in patients with rectal cancer - Results from the MERCURY study. Diseases of the Colon \& Rectum 2005;48(3):688-689.

\section{Enker 1999}

Enker WE, Merchant N, Cohen AM, Lanouette NM, Swallow C, Guillem J, Paty P, Minsky B, Weyrauch K, Quan SHQ. Safety and efficacy of low anterior resection for rectal cancer - 681 consecutive cases from a specialty service. Annals of Surgery 1999;230(4): $544-552$.

\section{Feliu 2002}

Feliu J, Calvillo J, Escribano A, de Castro J, Sanchez ME, Mata A, Espinosa E, Grande AG, Mateo A, Baron MG. Neoadjuvant therapy of rectal carcinoma with UFT-leucovorin plus radiotherapy. Annals of Oncology 2002;13(5):730-736.

\section{Glimelius 2002}

Glimelius B. Radiotherapy in rectal cancer. Br Med Bull 2002;64: $141-57$.

\section{Gray 2001}

Gray R, Hills R, Stowe R, Clarke M, Peto R, Buyse M, Piedbois P. Adjuvant radiotherapy for rectal cancer: a systematic overview of 8507 patients from 22 randomised trials. Lancet 2001;358(9290): 1291-1304.

\section{Heald 1982}

Heald RJ, Husband EM, Ryall RDH. The Mesorectum in RectalCancer Surgery - the Clue to Pelvic Recurrence. British Journal of Surgery 1982;69(10):613-616. [: 0007-1323]

\section{Heald 1998}

Heald RJ, Moran BJ, Ryall RDH, Sexton R, MacFarlane JK. Rectal cancer - The Basingstoke experience of total mesorectal excision, 1978-1997. Archives of Surgery 1998;133(8):894-898.

\section{Higgins 2008}

Higgins JPT, Green S (editors). Cochrane Handbook for Systematic Reviews of Interventions Version 5.0.0 [updated February 2008].. The Cochrane Collaboration. Available from www.cochrane-handbook.org. 2008.

\section{Holm 1996}

Holm T, Singnomklao T, Rutqvist LE, Cedermark B. Adjuvant preoperative radiotherapy in patients with rectal carcinoma Adverse effects during long term follow-up of two randomized trials. Cancer 1996;78(5):968-976.

\section{Kapiteijn 2001}

Kapiteijn E, Marijnen CAM, Nagtegaal ID, Putter H, Steup WH, Wiggers T, Rutten HJT, Pahlman L, Glimelius B, van Krieken J, Leer JWH, van de Velde CJH. Preoperative radiotherapy combined with total mesorectal excision for resectable rectal cancer. New England Journal of Medicine 2001;345(9):638-646.

\section{Mercier 2005}

Mercier M, Pasquet P, Puyraveau M, Bosset J, Calais G, Mineur L, Maingon P, Daban A, Bardet E, Collette L. Evaluation of the sphincter function and quality of life in French patients with rectal cancer who entered the EORTC 22921 study.. Eur J Cancer 2005; Supplements 3, No.2:171.

\section{Minsky 1993}

Minsky BD, Cohen AM, Kemeny N, Enker WE, Kelsen DP, Schwartz G, Saltz L, Dougherty J, Frankel J, Wiseberg J. Preoperative Combined 5-Fu, Low-Dose Leucovorin, and Sequential Radiation-Therapy for Unresectable Rectal-Cancer. International Journal of Radiation Oncology Biology Physics 1993;25 (5):821-827.

\section{Minsky 1997}

Minsky BD, Cohen AM, Enker WE, Saltz L, Guillem JG, Paty PB, Kelsen DP, Kemeny N, Ilson D, Bass J, Conti J. Preoperative 5-FU, low-dose leucovorin, and radiation therapy for locally advanced and unresectable rectal cancer. International Journal of Radiation Oncology Biology Physics 1997;37(2):289-295.

\section{Nagtegaal 2002}

Nagtegaal ID, Marijnen CAA, Kranenbarg EK, van de Velde CJH, van Krieken J. Circumferential margin involvement is still an important predictor of local recurrence in rectal carcinoma - Not one millimeter but two millimeters is the limit. American Journal of Surgical Pathology 2002;26(3):350-357.

\section{Osti 2004}

Osti MF, Valeriani M, Masoni L, Tombolini V, Enrici RM.

Neoadjuvant chemoradiation for locally advanced carcinoma of the rectum. Tumori 2004;90(3):303-309.

\section{Peeters 2005}

Peeters K, van de Velde CJH, Leer JWH, Martijn H, Junggeburt JMC, Kranenbarg EK, Steup WH, Wiggers T, Rutten HJ, Marijnen CAM. Late side effects of short-course preoperative radiotherapy combined with total mesorectal excision for rectal cancer: Increased bowel dysfunction in irradiated patients - A dutch colorectal cancer group study. Journal of Clinical Oncology 2005;23(25):6199-6206.

\section{Quirke 1986}

Quirke P, Dixon MF, Durdey P, Williams NS. Local Recurrence of Rectal Adenocarcinoma Due to Inadequate Surgical Resection Histopathological Study of Lateral Tumor Spread and Surgical Excision. Lancet 1986;2(8514):996-999. [: 0140-6736]

\section{Quirke 2003}

Quirke P. Training and quality assurance for rectal cancer: 20 years of data is enough. Lancet Oncology 2003;4(11):695-702.

\section{Rodel 2003}

Rodel C, Grabenbauer GG, Papadopoulos T, Hohenberger W, Schmoll HJ, Sauer R. Phase I/II trial of capecitabine, oxaliplatin, and radiation for rectal cancer. Journal of Clinical Oncology 2003;21 (16):3098-3104

\section{Sauer 2004}

Sauer R, Becker H, Hohenberger W, Rodel C, Wittekind C, Fietkau R, Martus P, Tschmelitsch J, Hager E, Hess CF, Karstens JH, Liersch T, Schmidberger H, Raab R. Preoperative versus postoperative chemoradiotherapy for rectal cancer. New England Journal of Medicine 2004;351(17):1731-1740.

\section{van den Brink 2004}

van den Brink M, Stiggelbout AM, van den Hout WB, Kievit J, Kranenbarg EK, Marijnen CAM, Nagtegaal ID, Rutten HJT, Wiggers T, van de Velde CJH. Clinical nature and prognosis of locally recurrent rectal cancer after total mesorectal excision with or 
without preoperative radiotherapy. Journal of Clinical Oncology 2004;22(19):3958-3964. [: 0732-183X]

* Indicates the major publication for the study 
CHARACTERISTICS OF STUDIES

\section{Characteristics of included studies [ordered by study ID]}

\section{Bosset 2006}

\begin{tabular}{|c|c|}
\hline Methods & $\begin{array}{l}\text { 1. Randomization method: telephone to central office (assumed) } \\
\text { 2. Abdominal imaging: CT } \\
\text { 3. Chest imaging: CXR } \\
\text { 4. } 4 \text { arm study: Arm } 1 \text { preop RT + S; Arm } 2 \text { preop XRT + concurrent } 5 \mathrm{FU} L V+S \text {;Arm } 3 \text { preop RT + S } \\
\text { + post op 5FU LV ; Arm } 4 \text { preop RTCT }+ \text { S + postop 5FU LV } \\
\text { 5. Total randomized } 1011\end{array}$ \\
\hline Participants & $\begin{array}{l}\text { 1. Rectal Cancer } \\
\text { 2. Location: within } 15 \mathrm{~cm} \text { from anal verge } \\
\text { 3. Resectability: locally resectable } \\
\text { 4. T3 or resectable T4 (defined by clinical criteria or endoscopic ultrasound) } \\
\text { 5. WHO PS } 0-1 \\
6 .<=80 \mathrm{yr}\end{array}$ \\
\hline Interventions & $\begin{array}{l}\text { 1.Surgery: AP/anterior resection or Hartman with TME } \\
\text { 2. RT : } 45 \mathrm{~Gy} \text { in } 25 \mathrm{fr} \text {. } \\
\text { 3. RT volume: } 5 \mathrm{~cm} \text { above and below tumor and perirectal nodes below } \mathrm{S} 2-3 \text {. If tumor above } 10 \mathrm{~cm} \text {, } \\
\text { include } \\
\text { only } 3 \mathrm{~cm} \text { above tumor. If tumor in low rectum, } \mathrm{S} 2-3 \text { to perineum. Posteriorly to include entire sacrum } \\
\text { with } 3 \mathrm{~cm} \text { beyond macroscopic extension } \\
\text { 4. RT-S: within } 3-10 \text { weeks of completing neoadjuvant therapy } \\
5.3 \text { or } 4 \text { field } \\
\text { 6. Chemotherapy: } 5 \mathrm{FU} 325 \mathrm{mg} / \mathrm{m} 2 / \mathrm{d} \text {; Leucovorin } 20 \mathrm{mg} / \mathrm{m} 2 / \text { day Dy } 1-5 \& 28-32 \text { for arms } 2 \text { and } 4 \text {, and } \\
\text { postoperative for arms } 3 \text { and } 4\end{array}$ \\
\hline Outcomes & $\begin{array}{l}\text { 1. Duration of FU: } 5.4 \text { yrs } \\
\text { 2. Perioperative mortality: CRTS } 2.4 \%(12 / 506) \text { RTS } 1.2 \%(6 / 505) \\
\text { 3. Mets (liver) @ lap: Y } \\
\text { 4. Curative resection: not stated } \\
\text { 5. Overall resection: } 94.5 \% \\
\text { 6. Compliance to radiotherapy: CRTS } 483 / 506(95.5 \%) \text { RTS } 495 / 505(98.0 \%) \\
\text { 7. OAS: Y } \\
\text { 8. CSS? } \\
\text { 9. Tox post RT: Y } \\
\text { 10. Acute tox post S: Y } \\
\text { 11. Late tox post S: Y } \\
\text { 12. LR: Y } \\
\text { 13. QOL: N } \\
\text { 14. Proportion sfincter sparing: CRTS } 267 / 506 \text { (52.8\%) RTS } 255 / 505(50.5 \%) \\
\text { 15. Proportion downstaging: Y }\end{array}$ \\
\hline Notes & \\
\hline
\end{tabular}

Risk of bias 


\section{Bosset 2006 (Continued)}

\begin{tabular}{l|ll}
\hline Item & Author' judgement & Description \\
\hline Allocation concealment? & Yes & A - Adequate \\
\hline
\end{tabular}

\section{Boulis-Wassif 1984}

\begin{tabular}{|c|c|}
\hline Methods & $\begin{array}{l}\text { 1.Randomization method: not stated. conducted by cooperative group. Likely via central office } \\
\text { 2. Abdominal imaging: Not stated } \\
\text { 3. Chest imaging: Not stated } \\
\text { 4. Study arm (Preop chemoradiotherapy arm) : 171 randomized, } 45 \text { excluded. } \\
\text { 5. Control arm (Preop radiotherapy arm): } 168 \text { randomized , } 47 \text { excluded }\end{array}$ \\
\hline Participants & $\begin{array}{l}\text { 1. Rectal Cancer } \\
\text { 2. Location: below within } 15 \mathrm{~cm} \text { anal verge } \\
\text { 3. Resectability: fit for surgery }\end{array}$ \\
\hline Interventions & $\begin{array}{l}\text { 1.Surgery: AP/anterior resection } \\
\text { 2. RT : } 3450 \mathrm{cGy} \text { in } 15 \mathrm{fr} \text {. (for both arms) } \\
\text { 3. BED: } 35.2 \mathrm{~Gy} 1 \\
\text { 4. RT volume: "chimney and diamond field " paraaortics and pelvis. } \\
\text { 5. RT-S: within } 2 \mathrm{wk} \\
\text { 6. } 2 \text { field } \\
\text { 7. Cointervention: none } \\
\text { 8. } 2 \text { arms, control (Radiotherapy followed by surgery), Study (Chemoradiotherapy followed by surgery) } \\
\text { 9.Chemotherapy: } 5 \mathrm{FU} 10 \mathrm{mg} / \mathrm{kg} / \mathrm{d} \text { day } 1-4\end{array}$ \\
\hline Outcomes & $\begin{array}{l}\text { 1.Duration of FU: mean 5.2yrs } \\
\text { 2. Perioperative mortality: CRTS 19/126 RTS 11/121 } \\
\text { 3. Mets @ lap: CRTS 13/126 RTS 15/121 } \\
\text { 4. Curative resection: Not stated } \\
\text { 5. Overall resection: CRTS 121, RTS } 124 \\
\text { 6. Compliance to radiotherapy: not given } \\
\text { 7. OAS: Y } \\
\text { 8. CSS: N } \\
\text { 9. Tox post RT: not given } \\
\text { 10: Acute tox post S: not given } \\
\text { No complication not given } \\
\text { 11. Late tox post S: not given } \\
\text { 12: LR: N } \\
\text { 13. QoL:N }\end{array}$ \\
\hline
\end{tabular}

\section{Risk of bias}

Item

Authors' judgement

\section{Description}


Boulis-Wassif 1984 (Continued)
Allocation concealment? Yes
A - Adequate

\section{Bujko 2006}

Methods

1.Randomization method: telephone to central office

2. Abdominal imaging: ultrasound or $\mathrm{CT}$

3. Chest imaging: CXR

4. XRT $+S$ arm : (short XRT) 155 randomized, 0 excluded.

5. Arm B: (Long XRT+CT): 157 randomized , 0 excluded

$\begin{array}{ll}\text { Participants } & \text { 1. Rectal Cancer } \\ \text { 2. Location: inferior edge palpable of digital exam } \\ \text { 3. Resectability: locally resectable } \\ \text { 4. T3 or resectable T4 } \\ \text { 5. not involving sphincter }\end{array}$

Interventions $\quad$ 1.Surgery: $\mathrm{AP} /$ anterior resection or Hartman with TME

2. RT : XRT $+S$ arm: $2500 c G y$ cGy in 5 fr. ; Arm B: $50.4 \mathrm{~Gy}$ in $28 \mathrm{fr}$ with concomitant CT weeks $1 \& 5$

3. BED: Arm A 38.7Gy10, Arm B 40.9Gy10

4. RT volume: Not stated

5. RT-S: XRT+S within 7 days; Arm B: within 4-6 weeks

6. 3 or 4 field

7. Arm B chemotherapy: 5 FU $325 \mathrm{mg} / \mathrm{m} 2 / \mathrm{d}$; Leucovorin $20 \mathrm{mg} / \mathrm{m} 2 /$ day Dy1-5 \& $28-32$

1.Duration of FU: not stated
2. Perioperative mortality: XRT+S 0/155 Arm B 0/157
3. Mets @ lap: not stated
4. Curative resection: not stated
5. Overall resection: XRT+S 145/155 Arm B 147/157
6. Compliance to radiotherapy: XRT+S 152/155 Arm B 141/157
7. OAS: $N$
8. CSS: N
9. Tox post RT: no complications XRT+S 118/155 Arm B 24/157 Any complications XRT+S $37 / 155$
Arm
B 133/157 Gd 3-4 XRT + S 5/155 Arm B 26/157 Gd 5 (Death) XRT +S 0/155 Arm B 2/157
10: Acute tox post S: Not stated
11. Late tox post S: not given
12: LR: N
13. QoL:N
14. Proportion sphincter sparing
15. Proportion downstaged (by T stage, N stage, Tumor size)

Notes

Risk of bias

$\begin{array}{lll}\text { Item Authors' judgement } & \text { Description }\end{array}$ 
Bujko 2006 (Continued)

Allocation concealment? Yes $\quad$ A - Adequate

\section{Gerard 2006}

\begin{tabular}{|c|c|}
\hline Methods & $\begin{array}{l}\text { 1. Randomization method: not stated } \\
\text { 2. Abdominal imaging: liver sonography - CT scan } \\
\text { 3. Chest imaging: CXR } \\
\text { 4. Study arm: CRT } 375 \\
\text { 5. Control arm: RT } 367\end{array}$ \\
\hline Participants & $\begin{array}{l}\text { 1. Rectal Cancer } \\
\text { 2. Location: accessible by digital examination } \\
\text { 3. Resectability: locally resectable }\end{array}$ \\
\hline Interventions & $\begin{array}{l}\text { 2 arms: preop XRT vs preop CRT } \\
\text { 1.Surgery: TME recommended } \\
\text { 2. RT } 45 \mathrm{~Gy} \text { in } 25 \mathrm{fr} \text { for both arms } \\
\text { 3. BED: } 32.5 \mathrm{~Gy} 10 \\
\text { 4. RT volume: NA } \\
\text { 5. RT-S: NA } \\
\text { 6. NA } \\
\text { 7. Cointervention: postoperative CT (5FU FA) } x 4 \text { cycles }\end{array}$ \\
\hline Outcomes & $\begin{array}{l}\text { 1.Duration of FU: } 81 \mathrm{~m} \\
\text { 2. Perioperative mortality ( } 60 \text { days): } 2 \% \text { for both arms } \\
\text { 3. Mets @ lap: not stated } \\
\text { 4. Curative resection: not stated } \\
\text { 5. Overall resection: not stated } \\
\text { 6. Compliance to radiotherapy: not stated } \\
\text { 7. OAS: Y } \\
\text { 8. CSS: Y } \\
\text { 9. Tox (gr 3-4) post RT: Preop RT arm: } 10 / 367 \text { CRT arm: } 55 / 375 \\
\text { 10: Acute tox post S: not stated } \\
\text { 11. Late tox post } S: Y\end{array}$ \\
\hline
\end{tabular}

\section{Risk of bias}

\begin{tabular}{l|ll}
\hline Item & Authors' judgement & Description \\
\hline Allocation concealment? & Yes & A - Adequate \\
\hline
\end{tabular}


DATA AND ANALYSES

Comparison 1. radiotherapy vs radiochemotherapy

\begin{tabular}{lccll} 
Outcome or subgroup title & $\begin{array}{c}\text { No. of } \\
\text { studies }\end{array}$ & $\begin{array}{c}\text { No. of } \\
\text { participants }\end{array}$ & Statistical method & Effect size \\
\hline 1 Overall Survival at 5y & 3 & 2000 & Odds Ratio (M-H, Fixed, 95\% CI) & $0.95[0.79,1.14]$ \\
2 Disease free survival at 5 y & 2 & 1753 & Odds Ratio (M-H, Fixed, 95\% CI) & $1.11[0.92,1.34]$ \\
3 Mortality 30 d & 4 & 2239 & Odds Ratio (M-H, Fixed, 95\% CI) & $1.48[0.84,2.60]$ \\
4 Postop morbidity & 3 & 1994 & Odds Ratio (M-H, Fixed, 95\% CI) & $0.84[0.68,1.03]$ \\
5 Grade III - IV toxicity & 3 & 2032 & Odds Ratio (M-H, Random, 95\% CI) & $4.10[1.68,10.00]$ \\
6 Sphincter preservation & 4 & 2219 & Odds Ratio (M-H, Fixed, 95\% CI) & $1.10[0.92,1.31]$ \\
7 pCR & 4 & 2201 & Odds Ratio (M-H, Fixed, 95\% CI) & $3.65[2.52,5.27]$ \\
8 Anastomotic leak & 3 & 1068 & Odds Ratio (M-H, Fixed, 95\% CI) & $1.03[0.57,1.85]$ \\
9 Local Recurrence at 5y & 3 & 1494 & Odds Ratio (M-H, Fixed, 95\% CI) & $0.53[0.39,0.72]$ \\
\hline
\end{tabular}

Analysis I.I. Comparison I radiotherapy vs radiochemotherapy, Outcome I Overall Survival at 5y.

\begin{tabular}{|c|c|c|c|c|c|}
\hline \multicolumn{6}{|c|}{ Comparison: I radiotherapy vs radiochemotherapy } \\
\hline \multicolumn{6}{|c|}{ Outcome: I Overall Survival at $5 y$} \\
\hline \multirow[t]{2}{*}{ Study or subgroup } & Treatment & Control & Odds Ratio & Weight & Odds Ratio \\
\hline & $n / N$ & $n / N$ & M-H,Fixed,95\% Cl & & M-H,Fixed,95\% Cl \\
\hline Bosset 2006 & $333 / 506$ & $327 / 505$ & $\overline{+}$ & $48.1 \%$ & $1.05[0.81,1.36]$ \\
\hline Boulis-Wassif 1984 & $58 / 126$ & $71 / 121$ & $\longrightarrow$ & $16.8 \%$ & $0.60[0.36,0.99]$ \\
\hline Gerard 2006 & $253 / 375$ & $249 / 367$ & + & $35.2 \%$ & $0.98[0.72,1.34]$ \\
\hline Total $(95 \% \mathrm{CI})$ & 1007 & 993 & $\bullet$ & $100.0 \%$ & $0.95[0.79,1.14]$ \\
\hline \multicolumn{6}{|c|}{ Total events: 644 (Treatment), 647 (Control) } \\
\hline \multicolumn{6}{|c|}{ Heterogeneity: $\mathrm{Ch}^{2}=3.78, \mathrm{df}=2(\mathrm{P}=0.15) ; \mathrm{I}^{2}=47 \%$} \\
\hline \multicolumn{6}{|c|}{ Test for overall effect: $Z=0.55(P=0.58)$} \\
\hline
\end{tabular}


Analysis I.2. Comparison I radiotherapy vs radiochemotherapy, Outcome 2 Disease free survival at 5 y. Review: Preoperative chemoradiation versus radiation alone for stage II and III resectable rectal cancer

Comparison: I radiotherapy vs radiochemotherapy

Outcome: 2 Disease free survival at 5 y

\begin{tabular}{|c|c|c|c|c|c|}
\hline \multirow[t]{2}{*}{ Study or subgroup } & Treatment & Control & Odds Ratio & \multirow[t]{2}{*}{ Weight } & Odds Ratio \\
\hline & $\mathrm{n} / \mathrm{N}$ & $\mathrm{n} / \mathrm{N}$ & M-H,Fixed,95\% Cl & & M-H,Fixed,95\% Cl \\
\hline Bosset 2006 & $284 / 506$ & $275 / 505$ & & $59.1 \%$ & $1.07[0.83,1.37]$ \\
\hline Gerard 2006 & $223 / 375$ & $204 / 367$ & & $40.9 \%$ & $1.17[0.88,1.57]$ \\
\hline Total (95\% CI) & 881 & 872 & 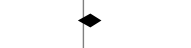 & $100.0 \%$ & $1.11[0.92,1.34]$ \\
\hline \multicolumn{6}{|c|}{ Total events: 507 (Treatment), 479 (Control) } \\
\hline \multicolumn{6}{|c|}{ Heterogeneity: $\mathrm{Chi}^{2}=0.22, \mathrm{df}=\mathrm{I}(\mathrm{P}=0.64) ; \mathrm{I}^{2}=0.0 \%$} \\
\hline \multicolumn{6}{|c|}{ Test for overall effect: $Z=1.10(P=0.27)$} \\
\hline
\end{tabular}

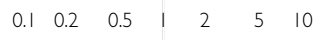

Favours treatment Favours control

\section{Analysis I.3. Comparison I radiotherapy vs radiochemotherapy, Outcome 3 Mortality $30 \mathrm{~d}$.}

Review: Preoperative chemoradiation versus radiation alone for stage II and III resectable rectal cancer

Comparison: I radiotherapy vs radiochemotherapy

Outcome: 3 Mortality $30 \mathrm{~d}$

\begin{tabular}{|c|c|c|c|c|c|}
\hline \multirow[t]{2}{*}{ Study or subgroup } & Treatment & Control & Odds Ratio & Weight & Odds Ratio \\
\hline & $n / N$ & $n / N$ & M-H,Fixed,95\% Cl & & M-H,Fixed,95\% Cl \\
\hline Bosset 2006 & $12 / 487$ & $6 / 483$ & 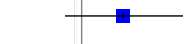 & $29.0 \%$ & $2.01[0.75,5.40]$ \\
\hline Boulis-Wassif 1984 & $11 / 124$ & $6 / 121$ & 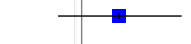 & $27.3 \%$ & $1.87[0.67,5.22]$ \\
\hline Bujko 2006 & $1 / 152$ & $2 / 153$ & & $9.8 \%$ & $0.50[0.04,5.57]$ \\
\hline Gerard 2006 & $7 / 359$ & $7 / 360$ & & $33.9 \%$ & $1.00[0.35,2.89]$ \\
\hline Total (95\% CI) & 1122 & 1117 & & $100.0 \%$ & $1.48[0.84,2.60]$ \\
\hline \multicolumn{6}{|c|}{ Total events: 3I (Treatment), 2I (Control) } \\
\hline \multicolumn{6}{|c|}{ Heterogeneity: Chi $^{2}=1.86, d f=3(P=0.60) ; I^{2}=0.0 \%$} \\
\hline \multicolumn{6}{|c|}{ Test for overall effect: $Z=1.37(P=0.17)$} \\
\hline
\end{tabular}

$\begin{array}{lllllll}0.1 & 0.2 & 0.5 & 1 & 2 & 5 & 10\end{array}$

Favours treatment Favours control 
Analysis I.4. Comparison I radiotherapy vs radiochemotherapy, Outcome 4 Postop morbidity.

Review: Preoperative chemoradiation versus radiation alone for stage II and III resectable rectal cancer

Comparison: I radiotherapy vs radiochemotherapy

Outcome: 4 Postop morbidity

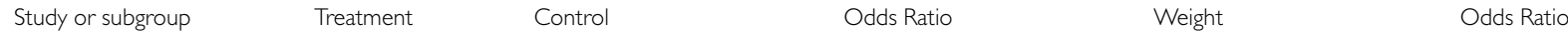

\begin{tabular}{|c|c|c|c|c|c|}
\hline & $\mathrm{n} / \mathrm{N}$ & $\mathrm{n} / \mathrm{N}$ & M-H,Fixed,95\% Cl & & M-H,Fixed,95\% Cl \\
\hline Bosset 2006 & | | |/487 & $112 / 483$ & $\rightarrow$ & $44.7 \%$ & $0.98[0.73,1.32]$ \\
\hline Bujko 2006 & $31 / 152$ & $39 / 153$ & $\longrightarrow$ & $15.9 \%$ & $0.75[0.44,1.28]$ \\
\hline Gerard 2006 & $75 / 359$ & $97 / 360$ & 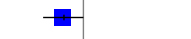 & $39.4 \%$ & $0.72[0.51,1.01]$ \\
\hline
\end{tabular}

Total $(95 \%$ CI $)$

998

996

$100.0 \%$

$0.84[0.68,1.03$ ]

Total events: 217 (Treatment), 248 (Control)

Heterogeneity: $\mathrm{Chi}^{2}=1.99, \mathrm{df}=2(\mathrm{P}=0.37) ; \mathrm{I}^{2}=0.0 \%$

Test for overall effect: $Z=1.66(P=0.096)$

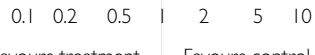

Favours treatment Favours control

\section{Analysis I.5. Comparison I radiotherapy vs radiochemotherapy, Outcome 5 Grade III - IV toxicity.}

Review: Preoperative chemoradiation versus radiation alone for stage II and III resectable rectal cancer

Comparison: I radiotherapy vs radiochemotherapy

Outcome: 5 Grade III - IV toxicity

\begin{tabular}{|c|c|c|c|c|c|}
\hline \multirow[t]{2}{*}{ Study or subgroup } & Treatment & Control & Odds Ratio & \multirow[t]{2}{*}{ Weight } & \multirow{2}{*}{$\begin{array}{r}\text { Odds Ratio } \\
\text { M-H,Random,95\% Cl }\end{array}$} \\
\hline & $\mathrm{n} / \mathrm{N}$ & $n / N$ & M-H,Random,95\% Cl & & \\
\hline Bosset 2006 & $67 / 483$ & $37 / 495$ & - & $38.4 \%$ & $1.99[1.31,3.04]$ \\
\hline Bujko 2006 & $29 / 157$ & $5 / 155$ & $\longrightarrow$ & $28.0 \%$ & $6.80[2.56,18.07]$ \\
\hline Gerard 2006 & $55 / 375$ & $10 / 367$ & $\longrightarrow$ & $33.6 \%$ & $6.14[3.08,12.24]$ \\
\hline Total (95\% CI) & 1015 & 1017 & & $100.0 \%$ & $4.10[1.68,10.00]$ \\
\hline \multicolumn{6}{|c|}{ Total events: I5I (Treatment), 52 (Control) } \\
\hline \multicolumn{6}{|c|}{ Heterogeneity: $\operatorname{Tau}^{2}=0.49 ; \mathrm{Chi}^{2}=10.57, \mathrm{df}=2(\mathrm{P}=0.0 \mathrm{I}) ; \mathrm{I}^{2}=81 \%$} \\
\hline \multicolumn{6}{|c|}{ Test for overall effect: $Z=3.10(P=0.0019)$} \\
\hline
\end{tabular}

$\begin{array}{lllllll}0.1 & 0.2 & 0.5 & 1 & 2 & 5 & 10\end{array}$

Favours treatment Favours control 
Analysis I.6. Comparison I radiotherapy vs radiochemotherapy, Outcome 6 Sphincter preservation. Review: Preoperative chemoradiation versus radiation alone for stage II and III resectable rectal cancer Comparison: I radiotherapy vs radiochemotherapy Outcome: 6 Sphincter preservation

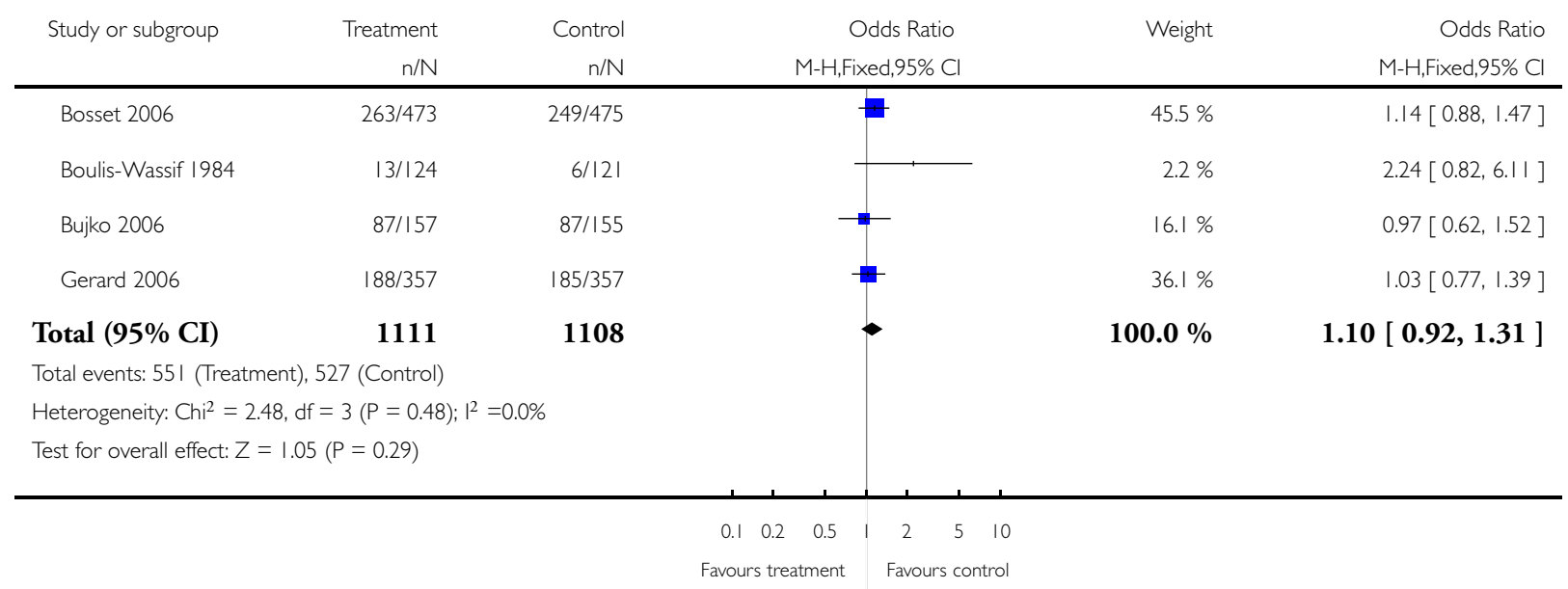

\section{Analysis I.7. Comparison I radiotherapy vs radiochemotherapy, Outcome 7 pCR.}

Review: Preoperative chemoradiation versus radiation alone for stage II and III resectable rectal cancer

Comparison: I radiotherapy vs radiochemotherapy

Outcome: 7 pCR

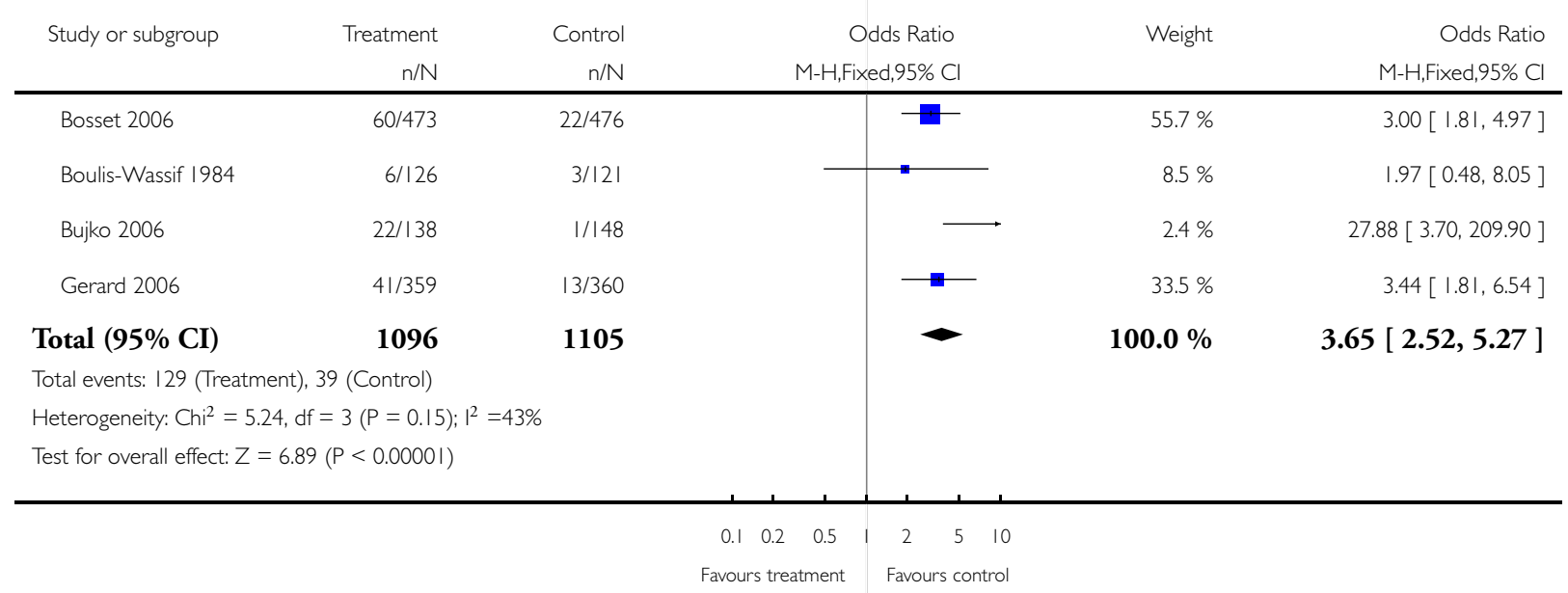




\section{Analysis I.8. Comparison I radiotherapy vs radiochemotherapy, Outcome 8 Anastomotic leak.}

Review: Preoperative chemoradiation versus radiation alone for stage II and III resectable rectal cancer

Comparison: I radiotherapy vs radiochemotherapy

Outcome: 8 Anastomotic leak

\begin{tabular}{|c|c|c|c|c|c|}
\hline \multirow[t]{2}{*}{ Study or subgroup } & Treatment & Control & Odds Ratio & Weight & \multirow{2}{*}{$\begin{array}{r}\text { Odds Ratio } \\
\text { M-H,Fixed,95\% Cl }\end{array}$} \\
\hline & $n / N$ & $n / N$ & \multicolumn{2}{|l|}{ M-H,Fixed,95\% Cl } & \\
\hline Bosset 2006 & $2 / 267$ & $0 / 255$ & $\longrightarrow$ & $2.3 \%$ & $4.81[0.23,100.7 \mid]$ \\
\hline Bujko 2006 & $8 / 87$ & $9 / 86$ & & $37.7 \%$ & $0.87[0.32,2.36]$ \\
\hline Gerard 2006 & $14 / 188$ & $14 / 185$ & & $59.9 \%$ & $0.98[0.45,2.12]$ \\
\hline Total $(95 \%$ CI $)$ & 542 & 526 & & $100.0 \%$ & $1.03[0.57,1.85]$ \\
\hline \multicolumn{6}{|c|}{ Total events: 24 (Treatment), 23 (Control) } \\
\hline \multicolumn{6}{|c|}{ Heterogeneity: $\mathrm{Chi}^{2}=1.1 \mathrm{I}, \mathrm{df}=2(\mathrm{P}=0.57) ; 1^{2}=0.0 \%$} \\
\hline \multicolumn{6}{|c|}{ Test for overall effect: $Z=0.09(P=0.93)$} \\
\hline
\end{tabular}

$\begin{array}{lllllll}0.1 & 0.2 & 0.5 & 1 & 2 & 5 & 10\end{array}$

Favours treatment Favours control

\section{Analysis I.9. Comparison I radiotherapy vs radiochemotherapy, Outcome 9 Local Recurrence at 5y.}

Review: Preoperative chemoradiation versus radiation alone for stage II and III resectable rectal cancer

Comparison: I radiotherapy vs radiochemotherapy

Outcome: 9 Local Recurrence at 5y

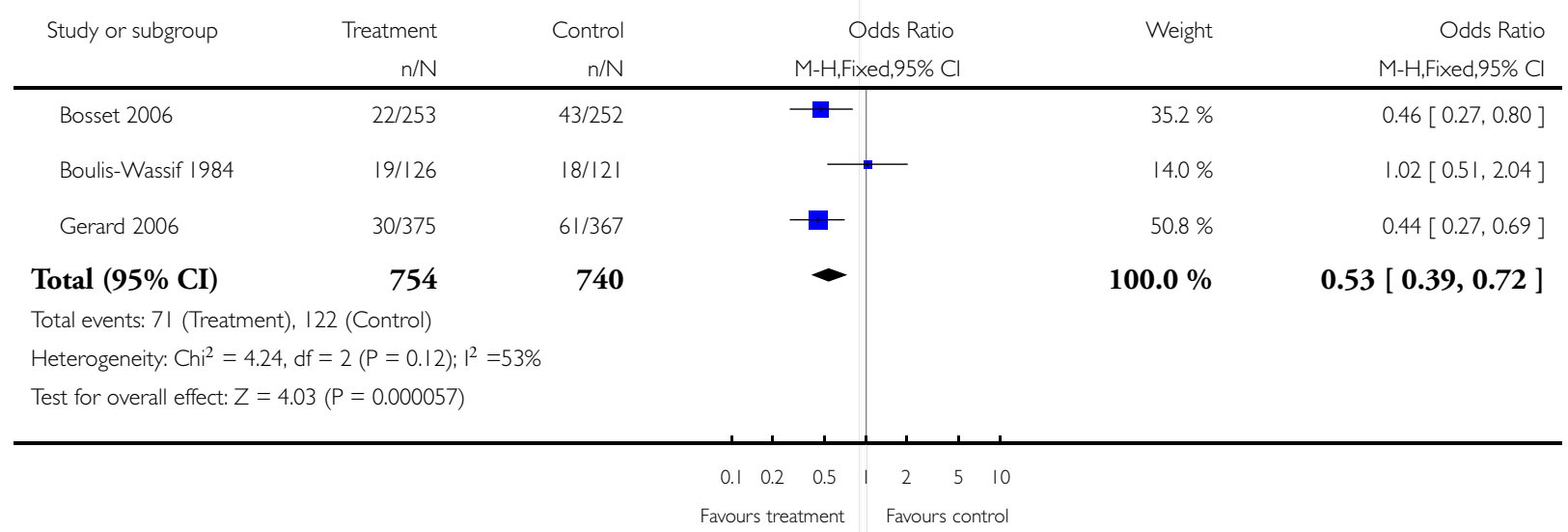




\section{WHAT'S NEW}

Last assessed as up-to-date: 1 September 2008.

27 May 2008 Amended Converted to new review format.

\section{H I S T O R Y}

Protocol first published: Issue 2, 2006

Review first published: Issue 1, 2009

26 February 2007 New citation required and conclusions have changed Substantive amendment

\section{CONTRIBUTIONS OFAUTHORS}

Drafted the protocol: WPC

Developed the search strategy: WPC

Searched for trials: WPC and YVN

Trials selection for inclusion: WPC and YVN

Data extraction: $\mathrm{KF}$

Data into revman analyses: $\mathrm{KF}$

Interpretation of analyses: WPC, YVN and KF

\section{DECLARATIONS OF INTEREST}

None.

\section{NDEX TERMS}

\section{Medical Subject Headings (MeSH)}

*Neoplasm Recurrence, Local [prevention \& control]; Randomized Controlled Trials as Topic; Rectal Neoplasms [*drug therapy; pathology; * radiotherapy; surgery] 


\section{MeSH check words}

Humans 